\title{
ENSINO MÉDIO INTEGRADO - DIÁLOGOS ENTRE A IMPLEMENTAÇÃO E PESQUISAS
}

\author{
Mariglei Severo Maraschin*, Cesar Augusto Robaina Filho, Leandro Lampe, Shirley \\ Bernardes Winter \\ *E-mail: mariglei@ctism.ufsm.br \\ Colégio Técnico Industrial de Santa Maria \\ DOI: $10.15628 /$ rbept.2020.11265
}

Artigo submetido em: set/2020 e aceito em: dez/2020

\begin{abstract}
RESUMO
Esta pesquisa tem por objetivo realizar um levantamento sobre os cursos de EMI e as pesquisas realizadas sobre esta temática em cursos de pós graduação das instituições públicas de ensino superior do estado do RS, disponibilizadas no Catálogo Nacional de Teses e Dissertações - Capes. Caracteriza-se como um estudo misto descritivo, aproximando-se de uma perspectiva explicativa. Os trabalhos encontrados, foram organizadas em três categorias que trataram sobre a Políticas Públicas e Gestão, Acesso, Evasão e Permanência e Práticas Pedagógicas. E os dados referentes aos cursos revelam aumento significativo de oferta, bem como enorme procura por esta possibilidade de formação. Em relação às pesquisas observou-se que se acentuaram após a instalação de um curso de pós graduação em rede sediado em instituições que ofertam também EMI.
\end{abstract}

Palavras-chave: Ensino Médio Integrado. Educação Profissional. Pesquisas.

\section{INTEGRATED HIGH SCHOOL - DIALOGUES BETWEEN IMPLEMENTATION AND RESEARCH}

\begin{abstract}
This research aims to carry out a survey on the Integrated High School courses and the research carried out on this theme in postgraduate courses of public institutions of higher education in the state of Rio Grande do Sul, available in the National Catalog of Theses and Dissertations. It is characterized as a mixed descriptive study, approaching an explanatory perspective. The works found were organized in three categories that dealt with Public Policies and Management, Access, Evasion and Permanence and Pedagogical Practices. And the data regarding the courses reveal a significant increase in supply, as well as a huge demand for this training possibility. In relation to research, it was observed that they were accentuated after the installation of a postgraduate course in a network based in institutions that also offer Integrated High School.
\end{abstract}

Keywords: Integrated High School. Professional Education. Researches. 


\section{INTRODUÇÃO}

Ao mencionar as modalidades de ensino que perpassam a educação profissional e tecnológica, destacam-se os ensinos I) subsequente caracterizado pela presença de estudantes que já concluíram a formação básica em nível médio buscando a formação profissional; II) concomitantes caracterizado pelo estudante que realiza sua formação básica de nível médio ao mesmo tempo que realiza formação profissional e tecnológica, entretanto não com currículos unificados; III) integrado - quando o estudante realiza a formação básica de nível médio ao mesmo tempo que a formação profissional e tecnológica e o curso apresenta integração curricular; como já estabelecidas no Decreto Lei N 11.741 de 2008.

O Ensino Médio Integrado com a EPT não é algo recente, e já tem suas indicações no capítulo III da primeira Lei de Diretrizes e Bases Lei $N^{\circ}$ 4.024/61 ao indicar como cursos técnicos possíveis para a época, sendo eles o curso industrial, agrícola e comercial que otimizavam o tempo de formação e de mão de obra, uma vez que esses cursos podem ser realizados durante os estudos ginasiais ou colegiais. A oferta de determinados cursos deve-se a situação socioeconômica do país, estritamente agricultura e comercial, vislumbrando a industrialização. $E$, por conta disso, passou estimular o preparo de profissionais para atuarem em determinadas áreas. A LDB 4.024/61, traz, em seu capítulo IV, apontamentos sobre o ensino Normal, que previa a formação de professores para atuarem nos anos iniciais da escolarização. Essa formação, ocorrendo simultaneamente ao ensino básico, compreende-se como uma modalidade de Ensino Médio Integrado. Entretanto, não faz menção sobre a formação de jovens e adultos, tão logo, ainda se apresenta inexistente a política de profissionalização na Educação de Jovens e Adultos - EJA/EPT.

Já em sua próxima versão, implementada no ano de 1971, momento em que o país já se encontrava em regime cívico-militar, acentuando a intenção de industrialização através de multinacionais estrangeiras se instalando em regiões que seriam posteriormente polos industriais. Desse modo, fez-se necessário a preparação de trabalhadores qualificados para atuarem nas indústrias, assim, estimulando a formação tecnicista, principalmente de caráter industrial. A nova Lei de Diretrizes e Bases Lei $N^{\circ}$ $5.692 / 71$, além de apresentar a educação agora dividida em $1^{\circ}$ e $2^{\circ} \mathrm{grau}$, torna obrigatória formação profissional articulada com o $2^{\circ}$ grau.

Apesar das imposições e limitações, a nova Lei apresenta a primeira intenção de atender aqueles que não tiveram a possibilidade de concluir os estudos no tempo adequado estipulado também pela legislação, que seria de 18 anos para o primeiro grau e de 21 para o segundo, em seu capítulo IV, faz menção ao ensino supletivo, assim podendo se inserir também na formação profissional. Com a nova lei que passa a apresentar o ensino em primeiro grau como obrigatório para o país, tem-se também reflexo sobre a demanda 
de professores, que destaca a possibilidade dos professores que haviam concluído sua formação em nível médio, ou seja, o curso Normal, ministrarem aulas para os anos iniciais do $1^{\circ} \mathrm{grau}$.

Na terceira versão da Lei de Diretrizes e Bases da educação, que está vigente atualmente, Lei № 9.394 de 1996, ao tratar da educação profissional no capítulo III, indica que a esta será apresentada em articulação com a formação regular. Apesar de seu Art ${ }^{\circ} 39$ indicar que "A educação profissional, integrada às diferentes formas de educação, ao trabalho, à ciência e à tecnologia, conduz ao permanente desenvolvimento de aptidões para a vida produtiva" (BRASIL, 1996), no seguinte ano com o Decreto № 2.208 de 1997, que estinguia a formação técnica profissional integrada ao nível médio motivado pelo custo elevado desta modalidade de ensino para os órgãos governamentais, além de outros fatores.

Apesar do Decreto Lei $N^{\circ} 11.741$ de 2008 apresentar encaminhamentos mais esclarecidos para a Educação Profissional e Tecnológica, além de desenvolvimentos e implementação de instituições federais que visavam prover esta modalidade de ensino articulada com a formação geral do estudante, posteriormente a ele pode-se evidenciar um apagamento das políticas sobre a EPT. Assim, apresenta-se como objetivo deste trabalho buscar em repositórios digitais das instituições públicas de ensino superior do estado do Rio Grande do Sul, trabalhos apresentados a programas de pós graduação, ou seja, dissertações e teses dos últimos cinco anos que tratem sobre o Ensino Médio Integrado, e o número de instituições que ofertam esta modalidade de ensino no estado do RS, estabelecendo uma análise e discussão entre dados obtidos.

\section{A POLÍTICA DE ENSINO MÉDIO INTEGRADO: UM PROCESSO DE AVANÇOS E RETROCESSOS}

Ao iniciar um breve levantamento das legislações que tratam de alguma forma da Educação Profissional e Tecnológica, é preciso destacar o decreto 2.208 de 1997, que entre outros aspectos aborda os objetivos da educação profissional e ainda apresenta os níveis básico, técnico e tecnológico, este último de nível superior para egressos do Ensino Médio e Ensino Técnico. O decreto que vigorou por sete anos, foi substituído pelo decreto 5.154 de 2004 que apresenta como característica possibilitar a continuidade dos estudos nos cursos de educação profissional, maior união entre teoria e prática, apresenta as modalidades integrado, concomitante e subsequente ao tratar da articulação entre educação básica e técnicaprofissionalizante.

Em 2007, a partir do decreto $N^{0}$ 6.302, foi institucionalizado o Programa Brasil Profissionalizado que entre seus oito objetivos para a Educação Profissional, objetivava principalmente aumentar e estimular a oferta de ensino médio integrado à educação profissional. De acordo com o Documento Base da Educação Técnica de Nível Médio Integrada ao Ensino 
Médio, divulgado ainda em 2007, é apresentada a intenção da ampliação de oferta para a educação profissional justificada pelos bons resultados apresentados por esta modalidade de ensino.

A oferta de Ensino Médio Integrado teve uma acentuada expansão a partir da criação dos Institutos Federais com a Lei $n^{0} 11.892 / 08$, de acordo com esta mesma legislação em seu segundo artigo, os IFs

\begin{abstract}
são instituições de educação superior, básica e profissional, pluricurriculares e multicampi, especializados na oferta de educação profissional e tecnológica nas diferentes modalidades de ensino, com base na conjugação de conhecimentos técnicos e tecnológicos com as suas práticas pedagógicas, nos termos desta Lei. (BRASIL, 2008).
\end{abstract}

Como apontado pela legislação responsável pela criação, implementação e regulamentação dos Institutos Federais a oferta de Educação Profissional e Tecnológica pode ser síncrona a formação básica de nível médio. Mas com vistas a atender a demanda de um público diversificado que busca qualificação profissional, também podem ser encontradas outras modalidades de ensino nestas instituições. Mas que como pode-se evidenciar com os estudos de Andrade e Melo (2020) "a proposta dos IF busca a superação da dualidade educacional existente, ao propor uma educação que possibilite ao indivíduo o desenvolvimento dos conhecimentos científicos e tecnológicos, de modo que estimule a emancipação humana."

De acordo com Ciavatta e Ramos (2011), "Ainda que sejamos levados a compreender o Ensino Médio Integrado à educação profissional como uma forma de relacionar processos educativos com finalidades próprias em um mesmo currículo, compreendemos integração como algo mais amplo". Para as autoras, o primeiro sentido que atribuímos à integração expressa uma concepção de formação humana que preconiza a integração de todas as dimensões da vida - o trabalho, a ciência e a cultura - no processo formativo. Tal concepção pode orientar tanto a educação geral quanto a profissional, independentemente da forma como são ofertadas. O horizonte da formação, nessa perspectiva, é a formação politécnica e omnilateral dos trabalhadores e teria como propósito fundamental proporcionar-lhes a compreensão das relações sociais de produção e do processo histórico e contraditório de desenvolvimento das forças produtivas.

Dentre as propostas de políticas que visavam contemplar a Educação Profissional e Tecnológica destaca-se também a criação do Plano Nacional de Educação, criado em 2014 (LEI No 13.005/14), que estabelece metas para serem atingidas em até dez anos, ou seja, até o ano de 2024. A metas que incidem de forma direta no Ensino Médio Integrado à Educação Profissional e Tecnológica são a de número 10 , que busca atingir no mínimo $25 \%$ das matrículas de jovens e adultos, no Ensino Fundamental e Ensino Médio de forma integrada à Educação Profissional; e a meta de número 11 que busca triplicar o número de matrículas na Educação Profissional Técnica de nível médio assegurando a qualidade da oferta, e ao menos $50 \%$ desta oferta ser pelo segmento público. 
Os dados e a situação do PNE são analisados pelo Ministério da Educação (MEC) a cada biênio, e assim divulgadas no Observatório Nacional de Educação. E, ao tratar da oferta de novas matrículas de Educação Profissional técnica na rede pública, a meta de número 11 apresenta informações referentes ao Gráfico 1. Pode-se observar um avanço no início da aplicação do plano, principalmente dos anos de 2014 a 2016 no Brasil, já ao realizar uma breve análise da situação do estado do Rio Grande do Sul, nota-se um aumento dos anos de 2014-2015 e posteriormente 2016-2017.

Figura 1: Relação entre ano e pontos percentuais de oferta de ensino profissional e técnico

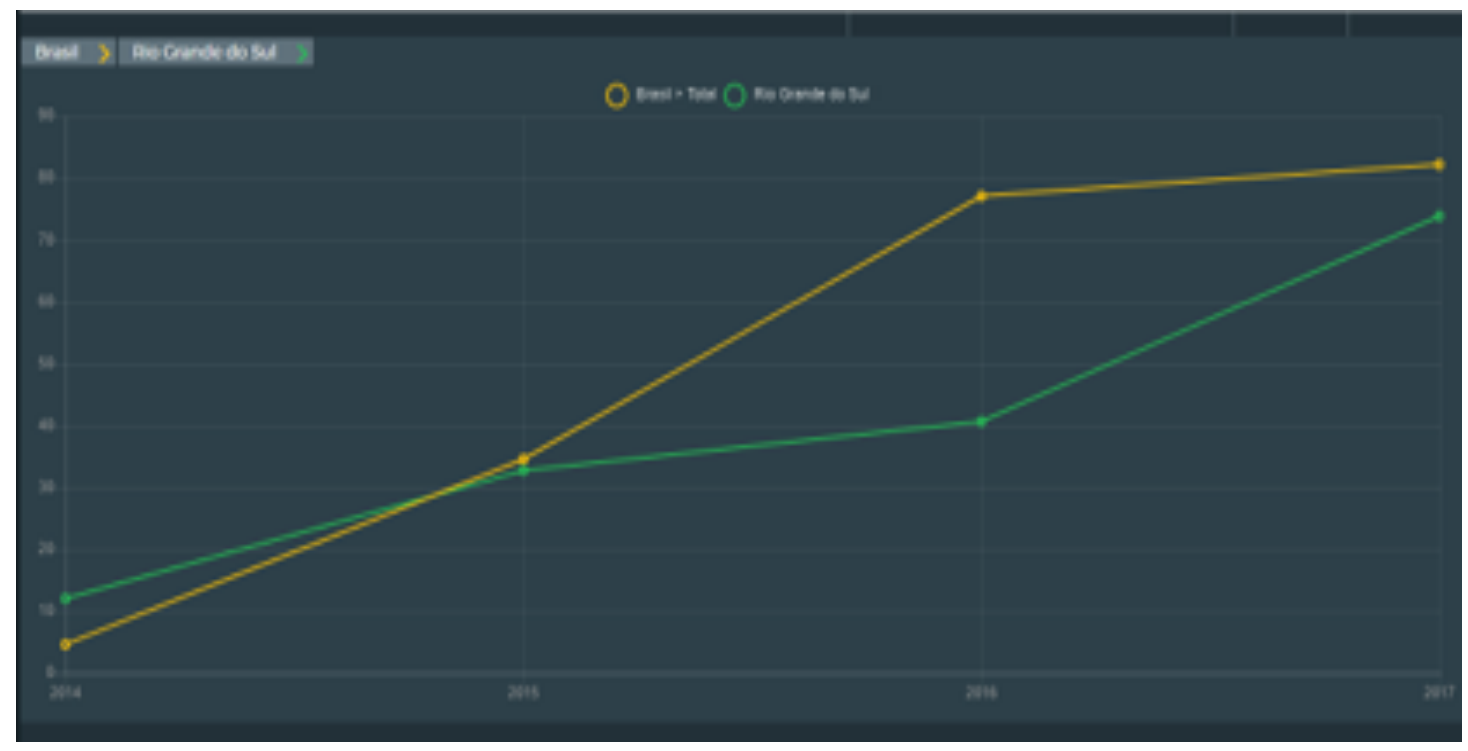

Fonte: Observatório Nacional de Educação. Acesso em: https:// www.observatoriodopne.org.br/

A legislação mais atual que trata da educação e do ensino, mais especificamente do Ensino Médio, a Base Nacional Comum Curricular para o Ensino Médio, aprovada em 2018, não destina ou faz menção ao Ensino Médio Integrado, nem a formação Profissional e Tecnológica. O diferencial desta nova proposta de Ensino Médio que já vem sendo implementada, são os itinerários formativos, que segundo o documento em uma possível aproximação com a Educação Profissional e Tecnológica, indica que "a expressão 'itinerário formativo' tem sido utilizada no âmbito da educação profissional, em referência à maneira como se organizam os sistemas de formação profissional ou, ainda, às formas de acesso às profissões" (BNCC, 2018; p. 467). No entanto, ao se tratarem dos itinerários formativos, é recorrente sua similaridade mais expressiva com a Lei de Diretrizes e Bases de 1971, que apresentava parte do currículo fixo e outra parte flexível, do que propriamente com a Educação Profissional e Tecnológica.

\section{METODOLOGIA}


O estudo que apresenta características das abordagens qualitativas e quantitativas pode ser designado como um estudo do tipo misto. Além disso, o estudo se trata de uma pesquisa documental e descritiva, que segundo Gil (2008), apresenta como característica fundamental a descrição de fatos, variáveis e fenômenos, que neste estudo, se trata da relação entre os estudos realizados por programas de pós graduação sobre as políticas do Ensino Médio Integrado.

O referido autor, indica a aproximação da pesquisa exploratória da perspectiva explicativa, assim, como o estudo busca determinar a natureza da relação entre o número de estudos e a oferta de Ensino Médio Integrado, a pesquisa se aproxima da perspectiva explicativa. Segundo Malhotra (2001), as pesquisas podem ser classificadas, em termos amplos, como exploratórias ou conclusivas. $\mathrm{E}$ as pesquisas conclusivas podem ser divididas em descritivas e causais. Já para Lakatos \& Marconi (1996) consideram que existem, basicamente, três tipos de pesquisa cujos objetivos são diferentes: pesquisa exploratória, descritiva e experimental. Mesmo com terminologias os autores relatam a pesquisa chegando ao mesmo objetivo

A pesquisa se desenvolveu através do Catálogo de Teses e Dissertações - CAPES. Como descritores para busca, foi empregado o termo "Ensino Médio Integrado". O período no qual foram filtrados os trabalhos foi de 2015 até 2019, nas instituições de ensino público que contavam com programas de pós-graduação. Além da consulta no Catálogo de Teses e Dissertações, foi feita a consulta aos dados abertos da plataforma Nilo Peçanha que aconteceu da seguinte maneira: foi selecionada a aba instituições, aplicado o filtro região sul, estado RS, organização acadêmica, escola técnica e Instituto Federal, instituição selecionando tudo, unidade de ensino selecionando tudo, modalidade de ensino presencial e a distância, tipo de curso, ensino médio e técnico, tipo de oferta integrado, nome do curso tudo, eixo tecnológico tudo, subeixo tecnológico tudo, fonte de financiamento tudo.

Ao tratar da análise dos dados obtidos através da pesquisa exploratória, será utilizada a análise descritiva, na qual busca-se a apresentação de dados estatísticos, mas não somente restritos a eles, e sim analisar e discutir os dados encontrados. De acordo com Mattar (2001), "Os Métodos Descritivos têm por objetivo proporcionar informações sumarizadas dos dados contidos no total de elementos estudados". Para Marconi \& Lakatos (1996), análise descritiva ou exploratória de dados é uma forma de utilizar técnicas estatísticas simples, para entender e explicar como os dados são ou podem ser. Para os autores a análise descritiva é o processo mais básico para qualquer tipo de análise de dados, embora simples em diversas ocasiões é um processo que, quando aliado a uma metodologia consistente, responde importante questões de maneira quase imediata.

\subsection{PLATAFORMA NILO PEÇANHA}


A Plataforma Nilo Peçanha (PNP), foi lançada pelo Ministério da Educação em março de 2018 como um mecanismo de acompanhamento dos resultados da Rede Federal. Esta ferramenta traz dados de mais de 650 unidades de ensino que pertencem a Rede Federal de Educação Profissional e Tecnológica, tais como, informações sobre oferta de cursos, matrículas, número de vagas e inscritos. A plataforma dispõe de dados e informações relevantes, podendo ser muito útil para pesquisadores. Está disponível no endereço eletrônico https://www.plataformanilopecanha.org e apresenta recursos inovadores de filtros de dados. A plataforma tem seus dados divididos em abas: instituições; tipos de cursos; eixo e subeixo tecnológico; situação de matrícula; cor e renda; sexo e faixa etária; professor; técnico administrativo em educação (TAE); gastos diretos; atendimento percentuais da Lei; relação inscritos/vaga; taxa de evasão; eficiência acadêmica; titulação docente; matrículas por professor e gasto corrente por matrícula.

\section{OS RESULTADOS QUE MOVEM O DIÁLOGO: A OFERTA E AS PESQUISAS DISPONÍVEIS}

\subsection{OS DADOS DE OFERTA}

Antes de se analisar a oferta a partir dos dados da plataforma Nilo Peçanha, realizou-se a busca das matrículas no Ensino Médio Integrado de 2015 à 2019 nos dados dos últimos 5 anos no Censo Escolar - Instituto Nacional de Estudos e Pesquisas Educacionais Anísio Teixeira (Inep), onde foram encontrados 10.270 matrículas em 2015, 11.479 matrículas em 2016, 12.316 em 2017, 13.102 em 2018 e 14.870 em 2019, como pode-se observar no gráfico abaixo:

Gráfico 1: Dados do Censo Escolar Inep de 2015 a 2019

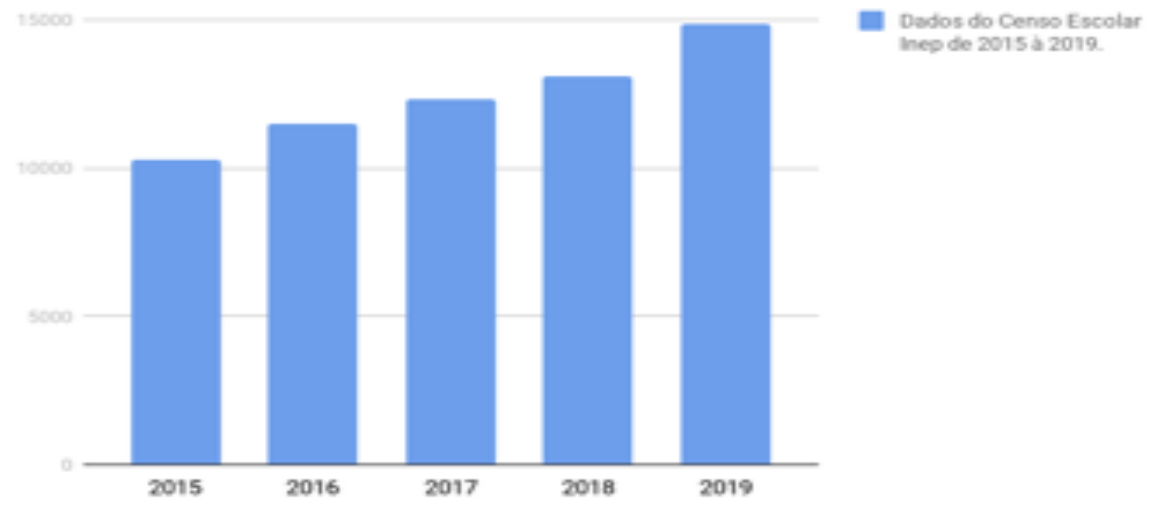

Fonte: Dados do Censo Escolar Inep. 
De acordo com a busca, conforme descrito na metodologia abordada nesta pesquisa e seguindo os filtros citados anteriormente, sobre a utilização da ferramenta Plataforma Nilo Peçanha, obtiveram-se como resultados para os anos de 2017, 2018 e 2019 no estado do Rio Grande do Sul, os dados apresentados no Quadro 1:

Quadro 1: Oferta de Ensino Médio Integrado no Rio Grande do Sul

\begin{tabular}{|c|c|c|c|c|c|c|c|}
\hline & Unidades & Cursos & Matrículas & $\begin{array}{c}\text { Ingressante } \\
\text { s }\end{array}$ & Concluintes & Vagas & Inscritos \\
\hline 2017 & 35 & 135 & 14.937 & 4.144 & 2.415 & 4.195 & 15.644 \\
\hline 2018 & 41 & 154 & 16.009 & 4.825 & 2.575 & 4.898 & 21.975 \\
\hline 2019 & 43 & 166 & 16.910 & 5.223 & 2.496 & 5.560 & 25.125 \\
\hline
\end{tabular}

Fonte: Plataforma Nilo Peçanha

Ao perceber a relação entre as unidades que ofertam a modalidade do Ensino Médio Integrado no estado do Rio Grande do Sul, e as produções realizadas em programas de pós graduação que tratam das políticas desta modalidade de ensino, evidencia-se uma diferença acentuada entre os números. Souza (2014), que tinha como objetivo em seu estudo identificar e analisar as temáticas abordadas nas pesquisas sobre as políticas educacionais, desenvolveu seu trabalho contando com as publicações dos trabalhos da Associação Nacional de Pesquisa e Pós-Graduação em Educação - ANPEd, e como resultados indica que as pesquisas que tratam das políticas educacionais estão relacionadas em sua maioria a gestão da educação, que envolve o sistema escolar, gestão democrática, entre outros.

Os resultados obtidos neste estudo, corroboram com os resultados encontrados por Souza (2014), uma vez que também foi encontrada uma carência nos estudos que tratem sobre as políticas da Educação Profissional e Tecnológica, mais precisamente sobre o Ensino Médio Integrado. $O$ fato de se haver uma carência dos estudos sobre o Ensino Médio Integrado, se mostra como uma situação complexa de ser estudada e analisada, uma vez que se apresenta como temática de linguagem formal e específica, e ainda segundo Souza (2014), grande parte dos estudos desenvolvidos acerca das políticas educacionais se mostram principalmente como análises políticas dos pesquisadores que possuem e apresentam sua ideologia, etc. remetendo fortemente a uma análise política do pesquisador, e não uma análise das políticas.

Além dos fatores mencionados, os estudos que abordam políticas sociais, inclusive as políticas educacionais, apresentam de certa forma um atraso em relação aos estudos gerados através delas. Pois, para que 
mobilizem os pesquisadores e sejam realizadas estudos a respeito, espera-se que tais políticas impactem, geram movimento e algum tipo de resultado, o que necessita de tempo específico.

\subsection{AS PESQUISAS SOBRE ENSINO MÉDIO INTEGRADO}

A partir da pesquisa realizada nos repositórios digitais das instituições federais de ensino superior, com os descritores acima mencionados, foram encontrados 28 pesquisas entre dissertações e teses, produzidos em diferentes instituições, sendo elas: Instituto Federal de Educ., Ciênc. e Tecn. Sul-Rio-Grandense com 6 produções; Instituto Fed. de Educ, Ciênc e Tecnologia Farroupilha com 5 produções; Universidade Federal de Santa Maria com 7 produções; Fundação Universidade Federal do Pampa com 1 produção; Universidade Federal do Rio Grande do Sul com 6 produções e Universidade Federal de Pelotas com 3 produções. A partir dos números, foi elaborado o Gráfico 2.

Gráfico 2: Relação das produções sobre Ensino Médio Integrado

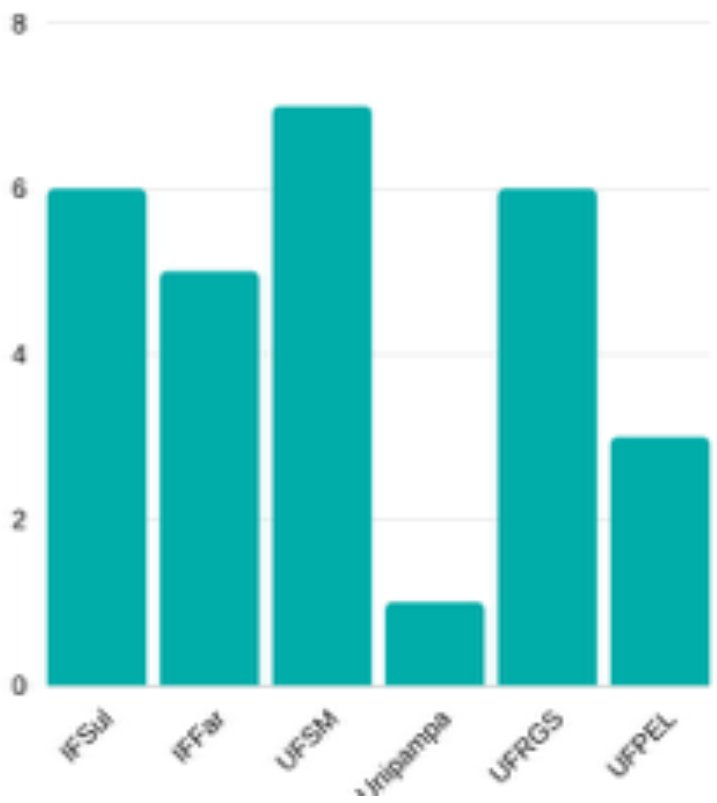

Fonte: os autores.

Outro aspecto analisado foi o ano em que pesquisas ocorreram, as quais 6 ocorreram em 2015, 3 em 2016, 1 em 2017, 5 em 2018 e 13 em 2019, como pode-se observar no Gráfico 3 abaixo. 
Gráfico 3: Distribuição das pesquisas sobre Ensino Médio Integrado em programas de pós graduação em cinco anos

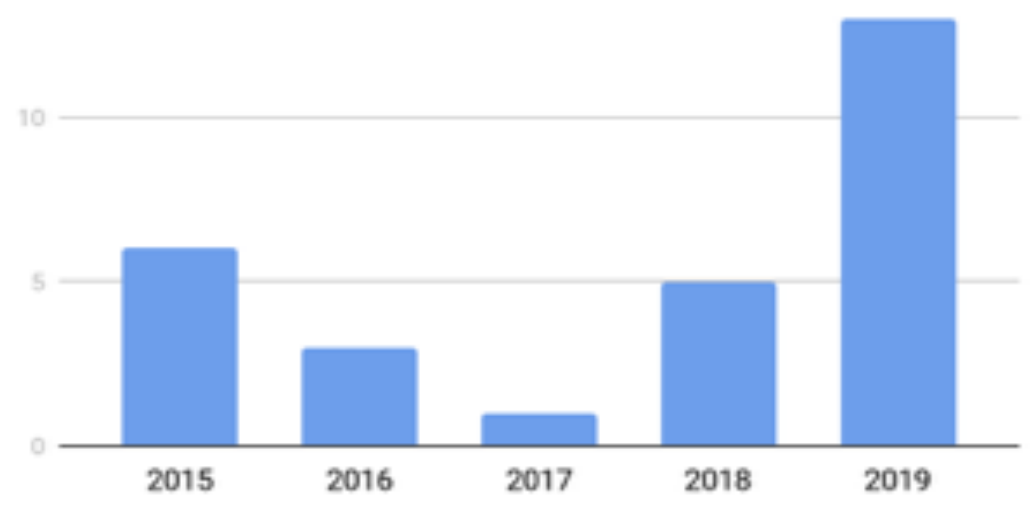

Fonte: os autores.

A intensificação das produções das pesquisas no ano de 2019, pode ser atribuída devido ao fato de ser o primeiro ano com turma de egressos do programa de pós-graduação Profissional em Educação Profissional e Tecnológica, um programa em rede implementado pelos Institutos Federais. O que pode ter contribuído de fato para a aproximação das pesquisas de pós graduação ao Ensino Médio Integrado.

Essas pesquisas encontradas, foram organizadas em três categorias temáticas, conforme apresentado no quadro abaixo. $\mathrm{Na}$ qual, a que apresentou maior número de trabalhos foi a categoria de Práticas Pedagógicas. Essa categoria engloba trabalhos que abordam as possibilidades de ações que buscam aprimorar o ensino e aprendizagem, mostrando-se relevante principalmente por conta da articulação síncrona entre a Educação Profissional e Tecnológica e da formação geral por meio do Ensino Médio Integrado, tratando dos desafios encontrados nessa modalidade, como as questões curriculares destes cursos. E assim, por vezes abordam temas envolvendo a atividade dos professores, o fator integrador entre a educação profissional e a formação geral, propostas pedagógicas para um currículo integrado, entre outros.

Em seguida, podem ser observados os estudos que se inserem na categoria de políticas e gestão, se mostrando relevantes para que ocorram discussões a partir da legislação e também das políticas locais, inerentes à própria instituição. Nessa categoria, foram encontrados estudos que abordam políticas de diferentes âmbitos, entre eles a inserção da mulher no Ensino Médio Integrado, a divisão sexual do trabalho em áreas técnicas, a própria relação entre políticas e práticas escolares, entre outros. No entanto, em grande parte dos estudos foram encontradas relações entres as políticas e gestão escolar, não evidenciando propriamente a política. $E$ a próxima categoria, menos expressiva quantitativamente, aborda questões referentes ao acesso, evasão e permanência na Educação Profissional e Tecnológica, 
abordando questões como práticas de acolhimento e estudos de caso para situações de evasão e permanência.

Quadro 2: Organização dos trabalhos encontrados em categorias temáticas

\begin{tabular}{|l|c|}
\hline \multicolumn{1}{|c|}{ Categorias } & Pesquisas \\
\hline Práticas Pedagógicas & 17 \\
\hline Acesso, Evasão e Permanência & 3 \\
\hline Políticas e Gestão & 8 \\
\hline
\end{tabular}

Fonte: os autores.

A partir dos resultados encontrados, observa-se um aumento do número de pesquisas envolvendo o Ensino Médio Integrado nos últimos anos. O que pode ser atribuído para a implementação de programas de pós graduação específicos para a Educação Profissional e Tecnológica, e que se encontram vinculados a instituições que apresentam cursos na modalidade de Ensino Médio Integrado. No entanto, ainda precisa-se avançar nos estudos referentes a essa modalidade de ensino, com vistas a contribuir e disseminar os bons resultados vivenciados pela comunidade escolar ao vivenciarem as oportunidades proporcionadas pelo Ensino Médio Integrado. Corrobora-se com Cardoso, Hammes e Boht (2020).

\begin{abstract}
Para que o EMI se afirme como uma proposta educacional contra hegemônica, os processos formativos voltados aos docentes devem necessariamente contemplar as reflexões políticas sobre educação, trabalho e sociedade, juntamente com as questões de ordem epistemológica. Nesse sentido, destaca-se a importância da compreensão crítica do mundo do trabalho pelo professor da educação profissional, para não se subordinar à lógica imposta pelo capital, mas, com qualidade técnica e política, propiciar a democratização do acesso à formação de qualidade. (CARDOSO, HAMMES e BOHT; 2020).
\end{abstract}

Corrobora-se com os apontamentos apresentados pelos autores acima, indicando a importância dos estudos envolvendo o Ensino Médio Integrado e sua respectiva política, para que assim, possa se consolidar e apresentar contribuições para um maior número de estudantes, por meio da formação profissional vinculada à formação geral.

\title{
5 CONSIDERAÇÕES FINAIS
}

No atual contexto em que se encontra a educação, e também a educação profissional e tecnológica no qual as propostas encaminham-se para o apagamento de propostas e políticas, mostram-se relevantes os estudos que apresentam como foco os cursos de Ensino Médio Integrado. 
Assim, justifica-se este estudo que realizou um levantamento dos trabalhos que versam sobre o Ensino Médio Integrado disponibilizados nos últimos cinco anos no Catálogo de Teses e Dissertações da Capes. Identificando a contribuição de programas de pós graduação específicos de Educação Profissional e Tecnológica para o aumento da discussão sobre políticas, gestão, acesso, evasão, permanência e práticas pedagógicas.

Com o presente estudo, evidencia-se o crescimento de pesquisas em programas de pós-graduação envolvendo a Educação Profissional e Tecnológica nas instituições federais do Rio Grande do Sul, em sua maioria relatando experiências e práticas pedagógicas nesta modalidade de ensino. Ainda é um campo que merece a atenção e estudos que possam compreender seu funcionamento e divulgar suas potencialidade e desafios.

Outro aspecto que ficou claro, foi do aumento das unidades, dos cursos, matrículas, ingressantes, concluintes, oferta de vagas e inscritos, mesmo que o número de concluintes tendo tido um pequeno regresso no ano de 2019, quando comparado com 2018, os demais itens demonstram um aumento considerável, quando comparados com os anos anteriores.

Por último com esta pesquisa pode-se perceber que a Educação Profissional e Tecnológica, está sendo cada vez mais procurada tanto por estudantes que saem do Ensino Fundamental e vão para o Ensino Médio Integrado, quanto por estudantes de Pós-Graduação que procuram a EPT como objeto de suas pesquisas. E, que assim, buscam atender essa demanda de estudos, e acabam por firmar a Educação Profissional e Tecnológica como campo sólido para promoção de aprendizagem, ensino e pesquisas.

\section{REFERÊNCIAS}

ANDRADE, Paula Danyelle Santana de; MELO, Sônia Pinto de Albuquerque. A OPÇÃO PELOS CURSOS DO ENSINO MÉDIO INTEGRADO. Revista Brasileira da Educação Profissional e Tecnológica, [S.L.], v. 2, n. 19, p. 1-19, 14 maio 2020. Instituto Federal de Educação, Ciência e Tecnologia do Rio Grande do Norte (IFRN). http://dx.doi.org/10.15628/rbept.2020.9895.

BRASIL. Base Nacional Comum Curricular (BNCC). Educação é a Base. Brasília, MEC/CONSED/UNDIME, 2018. Disponível em: <http://

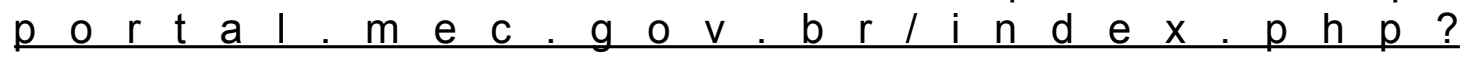
option=com docman\&view=download\&alias $=85121$-bncc-ensinomedio\&category_slug=abril-2018-pdf\&ltemid=30192> Acesso em 01 jul 2020.

BRASIL. DECRETO No 2.208, DE 17 DE ABRIL DE 1997. Regulamenta o § 2 ${ }^{\circ}$ do art. 36 e os arts. 39 a 42 da Lei $n^{\circ}$ 9.394, de 20 de dezembro de 1996, que estabelece as diretrizes e bases da educação nacional. Brasília, 1997. Disponível em <http://www.planalto.gov.br/ccivil_03/decreto/D2208.htm> Acesso em 01 jul 2020. 
BRASIL. DECRETO № 5.154 DE 23 DE JULHO DE 2004. Regulamenta o § $2^{\circ}$ do art. 36 e os arts. 39 a 41 da Lei $n^{\circ}$ 9.394, de 20 de dezembro de 1996, que estabelece as diretrizes e bases da educação nacional, e dá outras providências. Brasília, 2004. Disponível em <http://www.planalto.gov.br/ ccivil 03/ato2004-2006/2004/decreto/d5154.htm> Acesso em 01 jul 2020.

BRASIL. DOCUMENTO BASE: Secretaria de Educação Profissional e Tecnológica. Brasília, 2007. Disponível em: <http://portal.mec.gov.br/setec/ arquivos/pdf/documento base.pdf> Acesso em 01 jul 2020.

BRASIL. Lei de Diretrizes e Bases da Educação Nacional $n^{\circ}$ 9394/96. Brasília: 1996 Disponível em < http://portal.mec.gov.br/seesp/arquivos/pdf/ lei9394 Idbn1.pdf> Acesso em 28 set. 2020.

BRASIL. LEI No 11.892, DE 29 DE DEZEMBRO DE 2008. Institui a Rede Federal de Educação Profissional, Científica e Tecnológica, cria os Institutos Federais de Educação, Ciência e Tecnologia, e dá outras providências. Brasília, 2008. Disponível em <http://www.planalto.gov.br/ccivil 03/ Ato2007-2010/2008/Lei/L11892.htm> Acesso 01 jul 2020.

BRASIL. LEI No 13.005, DE 25 DE JUNHO DE 2014. Aprova o Plano Nacional de Educação - PNE e dá outras providências. Disponível em: <http:// www.planalto.gov.br/ccivil 03/ ato2011-2014/2014/lei//13005.htm> Acesso em 01 jul 2020.

CARDOSO, Ticiana Cougo; HAMMES, Itamar Luís; BOTH, Joseline Tatiana. A CONSTRUÇÃO DO ENSINO MÉDIO INTEGRADO: contribuições a partir de uma proposta de formação continuada no ifsul - câmpus pelotas. Revista Brasileira da Educação Profissional e Tecnológica, [S.L.], v. 2, n. 19, p. 1-26, 8 jun. 2020. Instituto Federal de Educacao, Ciencia e Tecnologia do Rio Grande do Norte (IFRN). http://dx.doi.org/10.15628/rbept.2020.9684.

CIAVATTA, Maria; RAMOS, Marise. Ensino Médio e Educação Profissional no Brasil: dualidade e fragmentação. Revista Retratos da Escola, Brasília, v. 5 , n. 8, p. 27-41, jan./jun. 2011. Disponível em: < http:// retratosdaescola.emnuvens.com.br/rde/article/viewFile/45/42> Acesso em 28 de set 2020.

Gil, Antonio Carlos. Métodos e técnicas de pesquisa social . 6. ed. - São Paulo : Atlas, 2008.

MALHOTRA, N. Pesquisa de marketing. 3.ed. Porto Alegre: Bookman, 2001.

MARCONI, M. A; LAKATOS, E. M. Técnicas de pesquisa: planejamento e execução de pesquisas, amostragens e técnicas de pesquisas, elaboração e interpretação de dados. 3.ed. São Paulo: Atlas, 1996.

PLATAFORMA NILO PEÇANHA - PNP 2018 (Ano Base 2017). Disponível em: <https://www.plataformanilopecanha.org/>. Acesso em: 08 dez. 2019. 
SOUZA, Ângelo Ricardo de. A pesquisa em políticas educacionais no Brasil: de que estamos tratando?. Praxis Educativa, v. 9, n. 2, p.355-367, jun. 2014. Universidade Estadual de Ponta Grossa (UEPG). 